\title{
'I am looking forward to returning to clinic'
}

\section{Dental therapy student Sophie Haddley ${ }^{\top}$ reflects on her experience during the COVID-19 pandemic.}

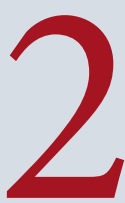

020 was a year that none of us will ever forget. Looking back on late 2019 and how dentistry was operating, compared to now, the contrast is unbelievable.

At the beginning of March 2020, I was a second-year dental therapy student at the University of the Highlands and Islands (UHI) based in Dumfries Dental Centre. I was seeing patients on clinic two days a week and spending the rest of my time in lectures. This soon changed and by the end of March, clinics had been cancelled and all lectures were online.

As a university that uses video conferencing to do lectures between our three centres (Dumfries, Inverness and Stornoway), we had very little in the way of issues in transitioning into online lectures as we were already set up in this way. This definitely helped alleviate stress in a very uncertain time. We were soon very used to logging onto

\section{Author information}

'Sophie has wanted to be a dental therapist since the age of 12 . She says: 'Dentistry is something that has always interested me and I found that it encompasses knowledge and practical application in an everyday job!'

Sophie became a dental nurse as she felt that experience seemed very important to most universities. She had failed her AS levels so decided that an apprenticeship in dental nursing was the best way to 'get her foot into the door of the dental world'! online lectures from home and interacting with each other online. In a way it brought us all closer together in a very lonely and strange time. As a cohort, we communicated increasingly via group chats. If we ever had any questions or queries, there was always someone to help with the answer. I definitely together when we were all staying at home and we were so far apart.

It soon came to the end of semester. With exams looming and assignments due, it was very strange to sit written exams via video conference online. It was a sharp contrast to sitting in a silent room with your peers quickly scribbling down an answer. Writing assignments also became quite a tricky experience. I think with the lack of established routine and having to stay at home,

motivation to get assignments completed was dwindling slightly. However, sitting our end of year clinical finals was a much more relaxed affair. We were able to do it in the comfort of our own homes, allowing us to feel more at ease when giving answers. As a cohort, we got ourselves through the final push and it was soon time to look ahead towards our third and final year.

Looking at going back to university at the end of August 2020, I felt apprehensive. Dentistry was only just getting back to its feet and in Scotland, routine appointments were still not available to patients. So many barriers were being put in our way and UHI were doing their absolute best to ensure a seam free and efficient return to university.

An early decision was made to make semester 1 of third year an academic semester. This meant we would be working from home. Instead of having two academic modules and a clinical module, we would complete three academic modules. This, in turn, would feel that social media brought us closer

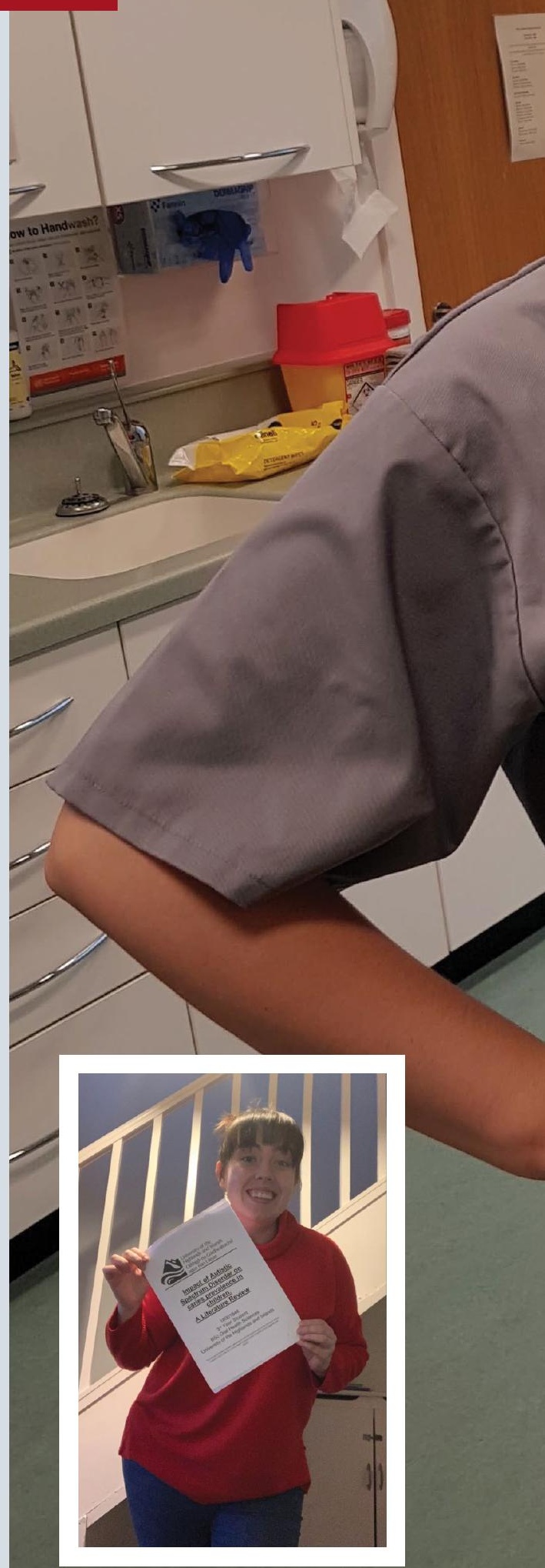




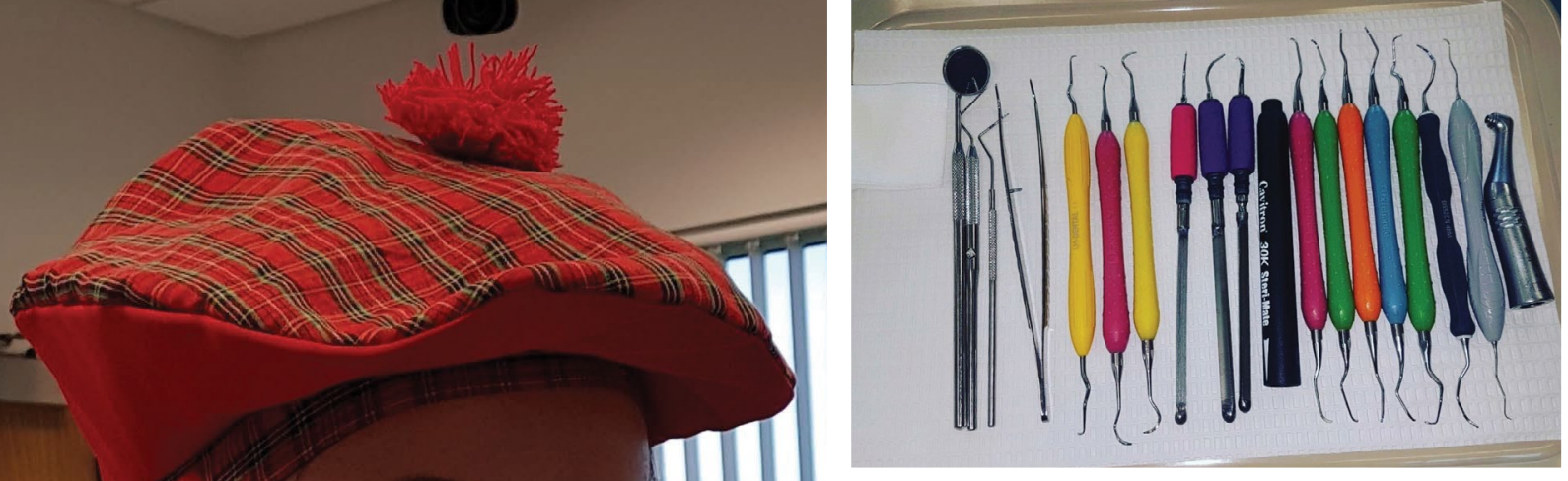

